\title{
The anti-biofouling effect against barnacles of a super-hydrophobic and high-oleophobic surface of treated aluminum
}

\author{
Yuji Ohkubo ${ }^{1), 2)}$, Kohtaro Kusu ${ }^{1)}$, Shogo Onishi ${ }^{1)}$, and Kazufumi Ogawa ${ }^{1)}$ \\ 1) Department of Advanced Materials Science, Graduate School of Engineering, Kagawa University, 2217-20 \\ Hayashi-cho, Takamatsu, Kagawa 761-0396, Japan \\ 2) Development and Research group, Kagawa Gakusei Venture Ltd., 1723-10 Takamatsu-cho, Takamatsu, Kagawa \\ 761-0104, Japan \\ *Corresponding author (Y.O.) E-mail: okubo@kgv.jp
}

(Received September 7, 2011; Accepted June 4, 2012)

\begin{abstract}
The effect of the low apparent solid surface energy of a specially engineered substrate on the settlement of barnacles was studied. To obtain an aluminum (Al) plate with low apparent solid surface energy, a plate was roughened by sandblasting and electrolytic chemical etching, and then coated with a chemically adsorbed monolayer (CAM) containing a fluorocarbon group. The plate was characterized by means of fluid contact angle measurements and a barnacle settlement test. The water contact angle (WCA) was $152^{\circ}$, and the oil contact angle of $n$-hexadecane (OCA) was $121^{\circ}$. The surface of the plate thus displayed super-hydrophobicity and high-oleophobicity. In addition, the wettability of this surface was evaluated, in terms of calculated apparent total solid surface energy, as approximately $1.6 \mathrm{mN} / \mathrm{m}$. In laboratory experiments, barnacles did not settle on the plate when exposed for 7 days. In comparison to controls using a variety of untreated and partially treated plates, this indicates that the surface treated to have low apparent solid surface energy can have an anti-biofouling effect, which may be explained by a combination of effects of relief and material.
\end{abstract}

Key words: anti-biofouling, barnacle settlement, super-hydrophobicity, micro- and nano-scale relief, apparent solid surface energy, fluorocarbon monolayer

\section{Introduction}

It is generally known that marine biofouling leads to a reduction in the propulsion efficiency of boats and ships and reduces the flow capacity of cooling water at thermal and atomic power plants (Sakaguchi, 2003; Sakaguchi and Namihira, 2006; Yamashita and Kamiya, 2006). The cause is the existence of millimeter- and centimeter-sized irregularities on the fouled surfaces, viz., the marine organisms that are attached there. Previously, paints containing tin (Sn) were used to prevent biofouling (Alberte et al., 1992; Ohkawa et al., 2000; Nogata, 2007), but the use of such paints has been restricted since 2001 under the International Convention on the Control of Harmful Anti-Fouling Systems on Ships (AFS treaty), because Sn is harmful to the environment. Paints containing copper $(\mathrm{Cu})$ have been developed as tin-free substitutes. Although the use of these paints is not yet regulated, some researchers have reported that $\mathrm{Cu}$ is also harmful to the environment (Mochida et al., 2006; Nogata, 2007). A novel technique that does not rely on paints containing heavy metals such as $\mathrm{Sn}$ and $\mathrm{Cu}$ is needed to imbue surfaces 
with anti-biofouling properties. The relationship between the wettability of a substrate and biofouling has been studied by some researchers, and the number of organisms attached to a surface is correlated to the solid surface energy of the substrate (Dahlstrom et al., 2004; Nogata, 2007). In particular, cypris larvae of barnacles prefer substrates with high solid surface energy (Gerhart et al., 1992). The converse, that the settlement of cypris larvae is reduced on substrates of low surface energy, has not been established. In the present we investigated the effect of low solid surface energy on biofouling behavior.

To prepare a suitable test substrate, a superhydrophobic and high-oleophobic surface was formed by sandblasting and electrolytic chemical etching of an aluminum (Al) plate, followed by the chemical modification of the plate surface using a chemically adsorbed monolayer (CAM) containing fluorocarbon groups. The anti-biofouling properties of this substrate were then evaluated by means of a settlement test using cypris larvae (barnacles).

\section{Materials and Methods \\ Materials}

Al plates $(50 \times 25 \times 2 \mathrm{~mm})$ were prepared by cutting a conventional Al board. As shown in Fig. 1, heptadecafluoro-1,1,2,2-tetrahydrodecyltrimethoxysilane

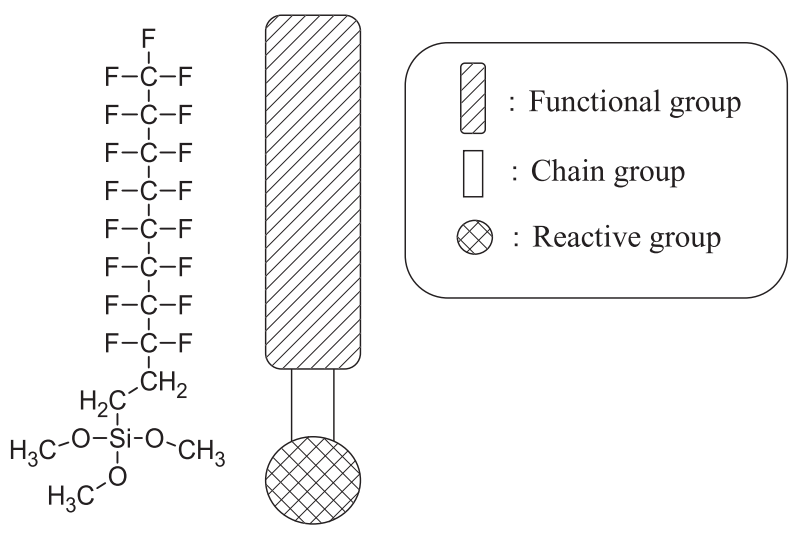

Fig. 1 Chemical formula of HDFS. This chemically adsorbent molecule is composed of three groups: the reactive group (spherical part), the chain group (white rectangular part), and the functional group (rounded rectangular part). The reaction group chemically reacts with the substrate. In this study, the trimethoxysilyl group is the reaction group, and the fluorocarbon group is the functional group. The fluorocarbon group decreases the surface energy on the surface of the $\mathrm{Al}$ substrate.
(HDFS; Toshiba Silicon Co., Ltd.) was used as a chemical adsorbent molecule to prepare a CAM containing fluorocarbon groups (HDFS-CAM) on the surface of each Al plate (Fukumoto and Ogawa, 2008; Tsuji et al., 2008; Tada et al., 2009; Yamamoto et al., 2009). Dehydrated chloroform (Wako Pure Chemical Industries, Ltd.) was used as a dilute solvent for the HDFS. The chloroform was dehydrated by the addition of a molecular sieve 4A (Nacalai Tesque, Inc.) for more than a week. Fluorochemical solvent (365LIVE; Yamato Chemicals Co., Ltd.) was used as an organic solvent for the HDFS adsorbent solution. Grained $\mathrm{Al}_{2} \mathrm{O}_{3}$ (grain type \#30, diameter range 707-595 $\mu \mathrm{m}$ ) was used for sandblasting. Phosphoric acid $\left(\mathrm{H}_{3} \mathrm{PO}_{4}\right.$; Wako Pure Chemical Industries, Ltd.) was used as a chemical etching solution for the Al plates. All chemicals were used without further purification.

\section{Sample Preparation}

A plate with a super-hydrophobic and higholeophobic surface was prepared in a six-step procedure as follows, according to the method described by Tsuji et al. (2008).

Step 1: An Al plate was cleaned for 5 min using chloroform, ethanol, and deionized water in sequence, and then annealed at $500^{\circ} \mathrm{C}$ for $10 \mathrm{~min}$ in a muffle furnace.

Step 2: A high degree of micro-scale relief was produced on the surfaces of the Al plate using sandblasting processing equipment (SGK-3, Japan Blast Process Researches Co., Ltd.) and grained $\mathrm{Al}_{2} \mathrm{O}_{3}$ at a pressure of $4 \mathrm{~kg} / \mathrm{cm}^{2}$ for $2.4 \mathrm{~s} / \mathrm{cm}^{2}$.

Step 3: A low degree of nano-scale relief was superimposed on the micro-scale relief by electrolytic chemical etching. An electrolytic direct current was applied between an Al plate roughened by sandblasting (anode) and a $\mathrm{Cu}$ electrode (cathode) in an electrolytic cell containing $\mathrm{H}_{3} \mathrm{PO}_{4}$ of $1 \mathrm{~N}$. The degree of relief was controlled by applying voltage while monitoring the current. The optimal current density and etching time were $1.44 \mathrm{~A} / \mathrm{cm}^{2}$ and $30 \mathrm{~s}$, respectively.

Step 4: The roughened Al plate was washed thoroughly to remove impurities such as dust and oil that can prevent the perfect formation of an HDFS-CAM. The plate was cleaned using an ultrasonic cleaner (US4R; AS ONE Co., Ltd.) with water for $5 \mathrm{~min}$ and then washed with ethanol for $5 \mathrm{~min}$ and chloroform for 5 min, in sequence. 
Step 5: An HDFS-CAM was formed on the roughened and cleaned Al plate. A dilute HDFS solution of $0.1 \mathrm{M}$ was prepared with dehydrated chloroform. An HDFS chemical adsorption solution of $5 \times 10^{-3} \mathrm{M}$ was prepared by adding the dilute solution to fluorochemical solvent (365LIVE). The roughened and cleaned Al plate was immersed in the HDFS chemical adsorption solution for $2 \mathrm{~h}$ at room temperature to allow the reaction of the methoxy groups $\left(-\mathrm{OCH}_{3}\right)$ of the HDFS with hydroxyl groups on the surface of the Al plate (Tsuji et al., 2008).

Step 6: After removing the Al plate from the HDFS chemical adsorption solution, the plate was air-dried at room temperature for $24 \mathrm{~h}$ to ensure complete reaction between the HDFS and the substrate surface to form an HDFS-CAM. The plate was then washed thoroughly as in step 4, using an ultrasonic cleaner with ethanol and chloroform in sequence to remove unreacted HDFS.

In addition, four kinds of $\mathrm{Al}$ plates were prepared for comparison by omitting one or more of the above steps as summarized in Table 1.

Table 1. Aluminum plate treatments and liquid droplet contact angles.

\begin{tabular}{c|ccc|cc}
\hline $\begin{array}{c}\text { Treatment } \\
\text { No. }\end{array}$ & sandblasting & $\begin{array}{c}\text { electrolytic } \\
\text { chemical } \\
\text { etching }\end{array}$ & HDFS-CAM & \multicolumn{2}{c}{ Contact angle [deg.] } \\
Water & $\begin{array}{c}\text { Hexadecane } \\
\text { (WCA) }\end{array}$ \\
\hline I & - & - & - & 22.9 & $<5.0$ \\
II & - & - & - & 104 & 54.3 \\
III & - & - & - & 135 & 73.3 \\
IV & - & - & - & 152 & 121 \\
V & - & - & - & $<5.0$ & $<5.0$ \\
\hline
\end{tabular}

\section{Evaluation of Substrate Surface}

The surface topography or relief of an Al plate roughened by sandblasting and electrolytic chemical etching was observed using a field emission scanning electron microscope (FE-SEM; Hitachi S-900, Hitachi Ltd.,). In order to prevent a buildup of static charge, a thin layer of platinum was deposited on the surface of the Al plate using sputtering system (Hitachi E-1030, Hitachi High-Technologies Corporation) prior to observation.

The surface topography of the Al substrate was also observed using an atomic force microscope (AFM; JSPM-4210, JEOL Ltd.,) before and after preparing the HDFS-CAM in order to confirm that the formation of the HDFS-CAM did not decrease the surface roughness or soften its relief. Silicon tips (NSC35/AIBS,
MikroMasch) were set on the cantilever and the $\mathrm{AC}$ mode was adopted. Images of $500 \times 500 \mathrm{~nm}$ area were obtained and WinSPM software was used to analyze the data.

An automatic contact angle meter equipped with a CCD camera (CA-VP150, Kyowa Interface Science Co, Ltd.) was used to measure the static contact angles of water and oil. Water purified using a cabinet-type water purifier (PRO-0100-002, Organo Corporation) was used to measure the water contact angle (WCA) to evaluate hydrophobicity, and $n$-hexadecane (Wako Pure Chemical Industries, Ltd.) was used as a hydrocarbon oil to measure the oil contact angle (OCA) to evaluate oleophobicity. The droplet volume was $3 \mu \mathrm{L}$. Photographs of droplets were automatically taken using a CCD camera one second after dropping them and the $\theta / 2$ method was applied to the photographs. The contact angles were measured at 7 different points around the circumference of each drop, and the mean of these data was taken after excluding the lowest and highest values. Before each measurement, the Al surface was washed to remove dust and oil, and then dried to remove the water.

The total solid surface energy $\gamma_{\mathrm{s}}{ }^{\text {total }}$ was calculated according to eqs. (1) and (2), derived by Kaelble and Uy (1970), Kaelble (1970), and Jańczuk et al. (1992), where $\theta$ is the experimental contact angle, and $\gamma$ is the surface energy. Subscripts $\mathrm{L}$ and $\mathrm{S}$ denote liquid and solid surfaces, respectively; superscripts $d$ and $p$ represent the dispersion and polar components of the surface energies, respectively. In eq. (1), the corresponding values of the above-mentioned parameters for water and $n$ hexadecane, $\gamma_{\mathrm{L}}{ }^{\mathrm{d}}$ and $\gamma_{\mathrm{L}}^{\mathrm{p}}$, were used; two equations that included two unknowns, $\gamma_{\mathrm{s}}{ }^{\mathrm{d}}$ and $\gamma_{\mathrm{s}}{ }^{\mathrm{p}}$, were derived. These unknowns were obtained by solving the simultaneous equations. The resulting values were used in eq. (2) to obtain $\gamma_{\mathrm{S}}^{\text {total }}$. Ordinarily, $\gamma_{\mathrm{s}}^{\text {total }}$ is obtained on a flat surface but it was obtained on a roughened surface in this study. To distinguish "apparent" surface energy $\gamma_{\mathrm{s}}{ }^{\text {total }}$ on a roughened surface from $\gamma_{\mathrm{s}}{ }^{\text {total }}$ on the flat surface, we define the latter as the "true" surface energy.

$$
\begin{aligned}
& \gamma_{L}{ }^{\text {total }}(1+\cos \theta)=2 \sqrt{\gamma_{S}{ }^{d} \gamma_{L}{ }^{d}}+2 \sqrt{\gamma_{S}{ }^{p} \gamma_{L}{ }^{p}} \\
& \gamma_{S}{ }^{\text {total }}=\gamma_{S}{ }^{d}+\gamma_{S}{ }^{p}
\end{aligned}
$$




\section{Barnacle Settlement Test}

Cypris larvae of Amphibalanus amphitrite were used for the barnacle settlement test. The preparation of the cypris larvae involved four steps.

Step 1: Adults of $A$. amphitrite that had naturally settled on bamboo rafts for oyster farming were collected from Lake Hamana in Japan and maintained in a circulation-type system at $23^{\circ} \mathrm{C}$ and fed on Artemia sp. (Nogata et al., 2011).

Step 2: Nauplius larvae hatched from these adults were collected using a pipette and moved to a beaker filled with filtered $(0.45 \mu \mathrm{m})$ natural seawater (salinity of $30 \mathrm{psu}$ ) containing penicillin $\mathrm{G}(30 \mathrm{mg} / \mathrm{L})$ and streptomycin sulfate $(66 \mathrm{mg} / \mathrm{L})$ and fed on Cheatoceros calcitrans $\left(2-3 \times 10^{5}\right.$ cells $/ \mathrm{mL}$ ) (Kado and Hirano, 1979; Matsumura et al., 2002). The nauplius larvae were reared at $23^{\circ} \mathrm{C}$ for 6 days, and consequently cypris larvae of $A$. amphitrite were obtained. During the entire period, aeration was continuous, but the filtered seawater was not changed.

Step 3: The cypris larvae were kept until bioassay under cold $\left(6.5^{\circ} \mathrm{C}\right)$ and dark conditions for 2 days (Satuito et al., 1996).

Step 4: The temperature of the seawater was restored to room temperature $\left(23^{\circ} \mathrm{C}\right)$ before the settlement test. The larvae were attracted by light, and actively swimming individuals were selected for the settlement test.

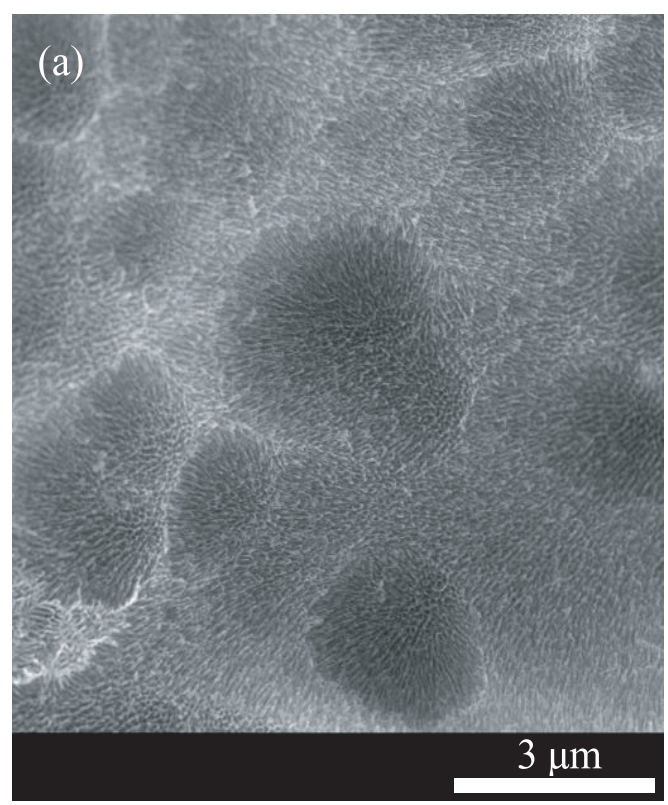

The test medium was prepared by placing the 150 $\mathrm{mL}$ of filtered $(0.45 \mu \mathrm{m})$ natural seawater (salinity of $30 \mathrm{psu}$ ) and $100 \pm 10$ cypris larvae into a polystyrene container. The $\mathrm{Al}$ test plates were immersed in this test medium for 1, 2, 3, 5, and 7 days and the attachment of the cypris larvae to the plates was observed. The medium was kept at room temperature $\left(23^{\circ} \mathrm{C}\right)$ in a dark room during the test. The settlement test was performed only one time for each Treatment.

\section{Results and Discussion}

FE-SEM images of the Al plate surface roughened by sandblasting and electrolytic chemical etching show micro-scale features like craters formed by sandblasting (Fig. 2a) and nano-scale features like needles formed by electrolytic chemical etching (Fig. 2b). Thus, microand nano-scale complex relief is obtained by combining these two processes.

An AFM image of the surface of the roughened $\mathrm{Al}$ substrate before HDFS-CAM preparation (Fig. 3a) shows a root mean square roughness $\operatorname{Rr}(\mathrm{a})$ of $31.4 \mathrm{~nm}$, and an average roughness $\mathrm{Ra}(\mathrm{a})$ of $25.9 \mathrm{~nm}$. After HDFS-CAM preparation (Fig. 3b), the root mean square roughness $\operatorname{Rr}(\mathrm{b})$ was $36.8 \mathrm{~nm}$, and the average roughness $\mathrm{Ra}(\mathrm{b})$ was $29.6 \mathrm{~nm}$. The measurement error of $\pm 5 \%$ and the molecular length of the HDFS $(<2$ $\mathrm{nm}$ ) do not preclude a conclusion that the HDFS deposition did not decrease the surface relief.

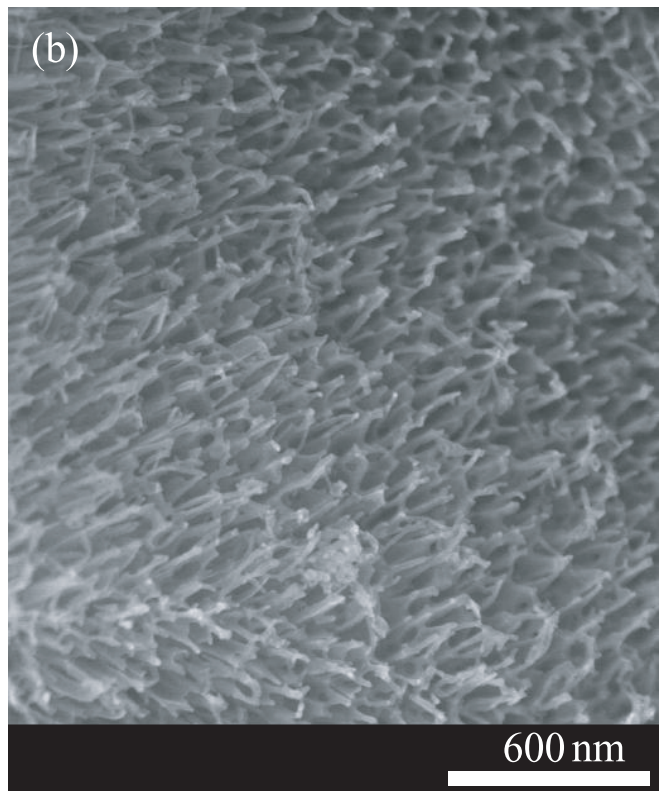

Fig. 2 FE-SEM images of the surface relief of the Al substrate roughened by sandblasting and electrolytic chemical etching; (a) $\times 10000,(b) \times 50000$. 

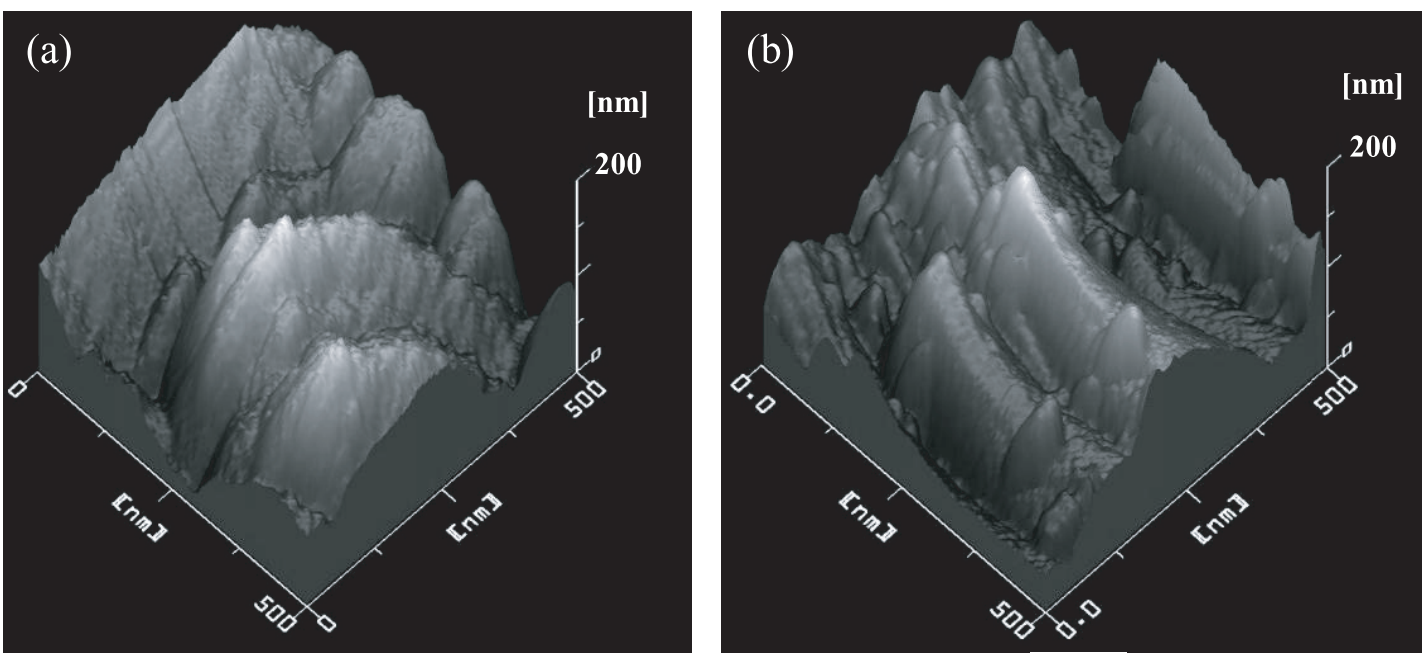

Fig. 3 AFM images of the surface of the Al substrate roughened by sandblasting and electrolytic chemical etching; (a) before HDFS-CAM formation, (b) after HDFS-CAM formation. Differences in topography are indicated by shading where by dark areas are low and light areas are high.
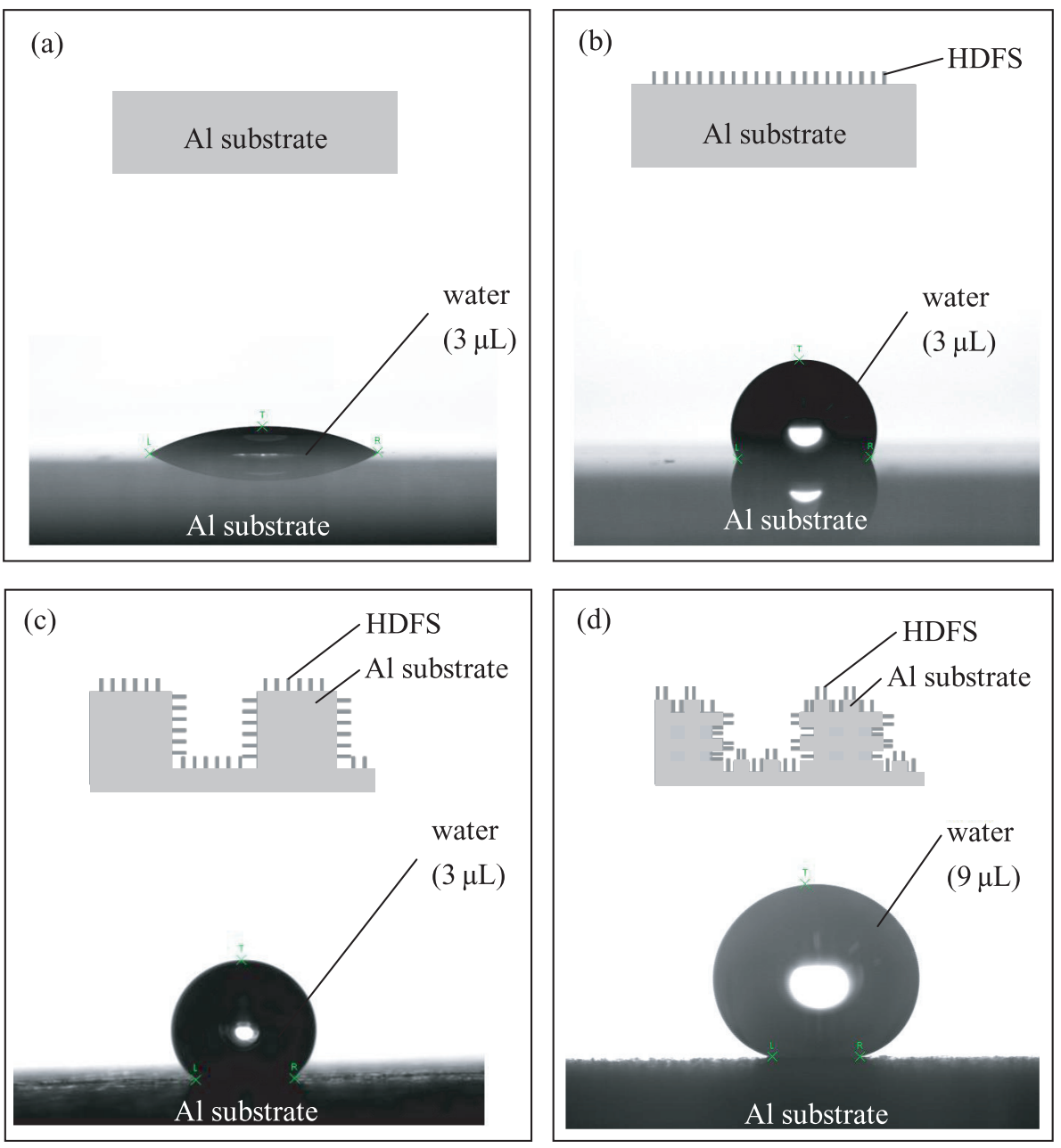

(d)

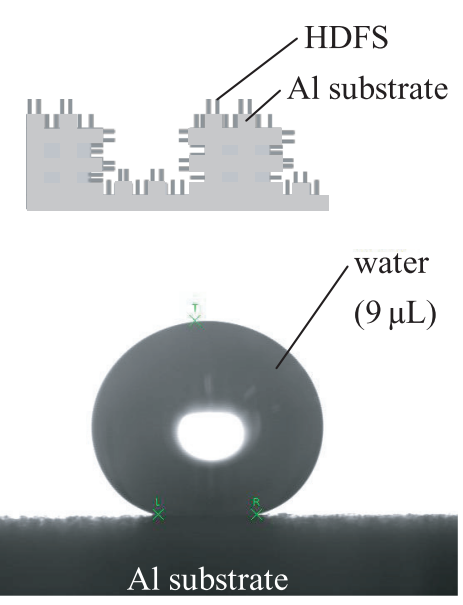

Fig. 4 Photographs of water droplets taken using a CCD camera; (a) on a Treatment I plate, (b) on a Treatment II plate, (c) on a Treatment III plate, (d) on a Treatment IV plate. 
As for water and oil droplet behavior, the WCA on the surface of an Al plate without HDFS-CAM (Treatment I) was $22.9^{\circ}$ (Fig. 4a), which indicates a hydrophilic surface. In contrast, the WCA and OCA on the surface of a flat Al plate modified with HDFS-CAM (Treatment II) were $104^{\circ}$ (Fig. 4b) and $54.3^{\circ}$, respectively. These results confirm that an HDFS-CAM indeed formed on the plate and that the originally hydrophilic surface became hydrophobic. An Al plate roughened by sandblasting and modified with HDFS (Treatment III) showed higher hydrophobicity (Fig. 4c) than the flat Al plate (Fig. 4b) because of the microscale relief. WCA could not be measured as above for the surface of an Al plate subjected to the full regimen of roughening by sandblasting and electrolytic chemical etching and modification with the HDFS (Treatment IV), since it was impossible to apply a droplet of $3 \mu \mathrm{L}$ to it. Therefore, the volume of the droplet was increased to $9 \mu \mathrm{L}$. WCA and OCA on the surface of Treatment IV were $152^{\circ}$ (Fig. 4d) and $121^{\circ}$, respectively. Thus, the surface of an Al plate roughened and modified with HDFS becomes not only super-hydrophobic but also highly oleophobic. On an Al plate just roughened by sandblasting and electrolytic chemical etching but not modified with HDFS-CAM (Treatment V), droplets of both water and $n$-hexadecane completely spread out soon after applying them. Both WCA and OCA of Treatment $\mathrm{V}$ were thus less than $5^{\circ}$ and impossible to measure accurately, owing to the super-hydrophilicity and super-oleophilicity of this surface.

In considering the total solid surface energy given from eqs. (1) and (2) for all samples, $\gamma_{\mathrm{s}}{ }^{\text {total }}$ decreases as the values of WCA and OCA increase (Table 2). The $\gamma \mathrm{s}^{\text {total }}$ of Treatment IV, which displayed superhydrophobicity and oleophobicity, was less than 2.0 $\mathrm{mN} / \mathrm{m}$, an ultralow apparent solid surface energy.

The correlation between the settlement ratio of barnacle cypris larvae and apparent solid surface energy is

Table 2. Solid surface energies given from eqs. (1) and (2) for all samples.

\begin{tabular}{c|ccc|cc|c}
\hline $\begin{array}{c}\text { Treatment } \\
\text { No. }\end{array}$ & sandblasting & $\begin{array}{c}\text { electrolytic } \\
\text { chemical } \\
\text { etching }\end{array}$ & HDFS-CAM & $\begin{array}{c}\gamma_{\mathrm{s}}{ }^{\mathrm{d}} \\
{[\mathrm{mN} / \mathrm{m}]}\end{array}$ & $\begin{array}{c}\gamma_{\mathrm{s}}{ }^{\mathrm{p}} \\
{[\mathrm{mN} / \mathrm{m}]}\end{array}$ & $\begin{array}{c}\gamma_{\mathrm{s}}{ }^{\text {total }} \\
{[\mathrm{mN} / \mathrm{m}]}\end{array}$ \\
\hline I & - & - & - & 27.5 & 40.5 & 68.0 \\
II & - & - & - & 17.3 & 1.35 & 18.7 \\
III & - & - & - & 11.4 & 0.543 & 11.9 \\
IV & - & - & - & 1.59 & 0.0522 & 1.64 \\
V & - & - & - & 27.5 & 45.5 & 73.0 \\
\hline
\end{tabular}

shown in Fig. 5. The settlement ratio on untreated Treatment I was $2.0 \%$ after 2 days and $7.8 \%$ after 3 days, lower than previous studies led us to expect (Ohkawa et al., 2000; Dahlstöm et al., 2004; Nogata et al., 2011). For example, we obtain a settlement ratio of ca. $60 \%$ on an untreated glass plate (Y. Ohkubo et al., unpublished data). The difference between the present results and other data might be explained by the materials effect of aluminum. Yamashita et al. (1990) reported that aluminum showed a lower settlement of balanomorph barnacles than other metals including brass, stainless steel, and titanium. Returning to our study, no larvae settled on the Treatment II plate for 2 days, but the settlement ratio increased gradually after that. The settlement ratio of Treatment III did not vary after 3 days although it was just $1.0 \%$ after 1 day. No larvae settled on the surface of the Treatment IV plate over the course of 7 days, confirming that the ultralow apparent $\gamma_{\mathrm{s}}{ }^{\text {total }}$ of this surface confers good antibiofouling properties. In our study, anti-biofouling properties seemed always to be enhanced with either decrease in the apparent $\gamma_{\mathrm{s}}^{\text {total }}$ or an increase in WCA. However, Treatment V (WCA of $<5^{\circ}$ ) had a lower settlement ratio than Treatment II (WCA of $103^{\circ}$ ). Dahlström et al. (2004) also reported that a hydrophilic polystyrene surface (WCA of $51^{\circ}$ ) had a lower settlement ratio than a hydrophobic one (WCA of $81^{\circ}$ ), and that a hydrophilic glass surface (WCA of $4^{\circ}$ ) had a lower settlement ratio than a hydrophobic one (WCA of $78^{\circ}$ ). Thus, anti-biofouling properties are not always enhanced with a decrease in the apparent $\gamma_{\mathrm{s}}^{\text {total }}$ or increase in WCA, but only for WCAs of over $100^{\circ}$. In fact, only on a hydrophobic surface, the surface with lower apparent $\gamma_{\mathrm{s}}{ }^{\text {total }}$ or higher WCA provided higher

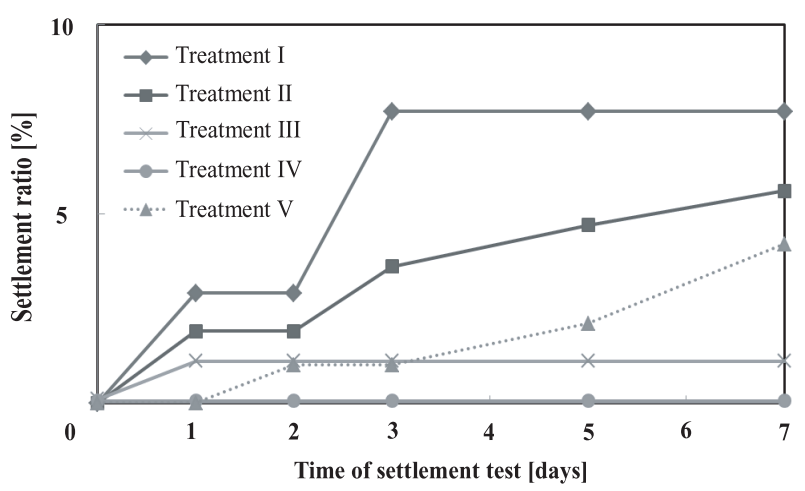

Fig. 5 Settlement ratio of cypris larvae over time for each treatment. 
anti-biofouling properties. As for hydrophilic surfaces, for now nothing can be said about the relationship between barnacle settlement and either high $\gamma_{\mathrm{s}}^{\text {total }}$ or low WCA.

Effects of both the surface relief and material are evident in Fig. 5. Treatment $\mathrm{V}$ had a lower settlement ratio than Treatment I, indicating that micro- and nanoscale relief prevents cypris larvae from settling on the surface; this is a relief effect, and it is consistent with several earlier studies on the anti-biofouling effects of micro-textured surfaces, with respect to barnacles. (Berntsson et al., 2000; Nogata, 2007; Horiuchi et al., 2009). In Treatment V, for example, observed effects can be explained by the decrease in contact points between the attachment region of the cypris larvae and the substrate surface. Treatment II resulted in a lower settlement ratio than Treatment I, which indicates that cypris larvae do not prefer substrates with low real surface energy. If so, this is a material effect because the plate surfaces in both Treatments I and II were flat and there thus can be no relief effect. In addition, Treatment $\mathrm{V}$ also resulted in a lower settlement ratio than Treatment II. This indicated that the relief effect contributes more to the anti-biofouling effect than the material effect does. Treatment IV had the lowest settlement ratio. This is explainable as a result of a combination of the material and relief effects because Treatment IV had not only the HDFS-CAM treatment but also micro- and nano-scale relief, thus combining the properties of Treatments II and V.

Table 3 shows the proportions of damaged cypris larvae in the settlement test. Damaged cypris larva was defined as an individual that was not swimming actively, or was unresponsive to stimulus or dead. None were damaged during the first 5 days in Treatment I-V. It is especially notable that no larvae died in Treatment

Table 3. Proportions (\%) of damaged cypris larvae in each treatment in the settlement test.

\begin{tabular}{c|ccccc}
\hline $\begin{array}{c}\text { Treatment } \\
\text { No. }\end{array}$ & 1 & 2 & 3 & 5 & 7 \\
\hline I & 0.0 & 0.0 & 0.0 & 0.0 & 1.0 \\
II & 0.0 & 0.0 & 0.0 & 0.0 & 0.9 \\
II & 0.0 & 0.0 & 0.0 & 0.0 & 3.3 \\
IV & 0.0 & 0.0 & 0.0 & 0.0 & 0.0 \\
V & 0.0 & 0.0 & 0.0 & 0.0 & 8.3 \\
\hline
\end{tabular}

IV during the test. Furthermore, most of cypris larvae were free swimming in Treatment IV as well as Treatment I. The anti-biofouling properties of superhydrophobicity and high-oleophobicity surface, with low apparent $\gamma_{\mathrm{s}}^{\text {total }}$, appear to work without killing the cypris larvae.

\section{Conclusion}

In this study, we investigated the anti-biofouling property of an Al plate with a super-hydrophobic and high-oleophobic engineered surface texture. Such the plate with micro- and nano-scale relief was prepared by sandblasting and electrolytic chemical etching, and then allowing an HDFS-CAM to form; the apparent $\gamma_{\mathrm{s}}^{\text {total }}$ of the plate was $<2 \mathrm{mN} / \mathrm{m}$. No cypris larvae became attached to the plate when exposed in the laboratory for 7 days. This is explained by a combination of relief effects and material effects. Furthermore, the cypris larvae were free swimming and none died during the test. This suggests that our technique can provide antibiofouling properties without causing damage to the cypris larvae and in this respect may prove to be a relatively green technology compared to anti-biofouling paints.

This combinatorial technique holds the promise of higher-level technology for anti-biofouling materials. Although we used only one kind of silane coupling agent with fluorocarbon groups, and focused on $\gamma_{\mathrm{s}}{ }^{\text {total }}$, Ohkawa et al. (2000) prepared modified flat glass substrates using several kinds of silane coupling agents not including fluorocarbon groups, and compared the individual effects of each $\gamma_{\mathrm{s}}{ }^{\mathrm{d}}$ and $\gamma_{\mathrm{s}}^{\mathrm{p}}$ on anti-biofouling. They concluded that barnacle larva exhibited reduced settlement on the glass substrates having a surface energy that is smaller in terms of $\gamma_{\mathrm{s}}{ }^{\mathrm{p}}$ but larger $\gamma_{\mathrm{s}}{ }^{\mathrm{d}}$. The fluorocarbon group used in our study displays small values of $\gamma_{\mathrm{s}}{ }^{\mathrm{d}}$ and $\gamma_{\mathrm{s}}{ }^{\mathrm{p}}$, so if silane coupling agents such as amino-silane, chloro-silane, and mercapto-silane et al. were applied to surfaces of micro- and nano-scale relief, our technique could result in even greater antibiofouling properties. As the next step, the utility of such substances in combination with micro- and nanoscale relief effect of $\gamma_{\mathrm{s}}{ }^{\mathrm{d}}$ and $\gamma_{\mathrm{s}}{ }^{\mathrm{p}}$ should be investigated.

\section{Acknowledgments}

This work was supported by the Japan Aerospace Exploration Agency (JAXA). The barnacle settlement 
test was performed in collaboration with the Sessile Research Corporation. We particularly wish to thank K. Yamashita, K. Kamiya, and co-workers at the Sessile Research Corporation. In addition, we thank Y. Nogata at Research Institute of Electric Power Industry and T. Ohkawara of the Oyster Cultivation Society of Maisaka-cho for their assistance in collecting adults of A. amphitrite from Lake Hamana.

\section{References}

Alberte, R. S., S. Snyder, B. J. Zahuranec, and M. Whetstone (1992). Biofouling research needs for the US Navy: program history and goals. Biofouling, 6, 91-95.

Berntsson, K. M., P. R. Jonsson, M. Lejhall, and P. Gatenholm (2000). Analysis of behavioural rejection of micro-textured surfaces and implications for recruitment by the barnacle Balanus improvisus. J. Exp. Mar. Biol. Ecol., 251, 59-83.

Dahlström, M., H. Jonsson, P. R. Jonsson, and H. Elwing (2004). Surface wettability as a determinant in the settlement of the barnacle. J. Exp. Mar. Biol. Ecol., 305, 223232.

Fukumoto, T. and K. Ogawa (2008). Controlling the marching velocities of capillary meniscus in the channel of the chemical chip by surface energy control. J. Surface Finishing Soc. Jpn., 59, 57-62. (in Japanese)

Gerhart, D. J., D. Rittschof, I. R. Hooper, K. Eisenman, A. E. Mayer, R. E. Baier, and C. Young (1992). Rapid and inexpensive quantification of the combined polar components of surface wettability. Biofouling, 5, 251-259.

Horiuchi R., S. Kobayashi, Y. Kameyama, M. Mizutani, J. Komotori, and I. Katsuyama (2009). Barnacle settlement behavior on controlled microtextured surfaces. Corrosion Eng., 58, 369-378.

Jańczuk, B., M. L. Kerkeb, T. Biatrowicz, and F. GonzálezCaballero (1992). Surface free energy of cholesterol and bile salts from contact angles. J. Colloid Interface Sci., 151, 333-342.

Kado, R. and R. Hirano (1979). Rearing methods of planktonic larvae of marine sessile animals. Mar. Fouling, 1, 11-19. (in Japanese)

Kaelble, D. H. (1970). Dispersion-polar surface tension properties of organic solids. J. Adhesion, 2, 66-81.

Kaelble, D. H. and K. C. Uy (1970). Reinterpretation of organic liquid- polytetrafluoroethylene surface interactions. J. Adhesion, 2, 50-60.

Matsumura, K., K. Yamashita, K. Kamiya, Y. Okada, T. Yanagawa, Y. Oka, and T. Kawabata (2002). Important roles of settlement-inducing proteins and nature of substrata in larval settlement of the barnacles Balanus amphitrite and Megabalanus rosa. Sessile Organisms, 19, 93-99. (in Japanese)

Mochida, K., K. Ito, H. Harino, A. Kakuno, and K. Fujii (2006). Acute toxicity of pyrithione antifouling biocides and joint toxicity with copper to red sea bream (Pagrus major) and toy shrimp (Heptacarpus futilirostris). Environ. Toxicol. Chem., 25, 3058-3064.

Nogata, Y. (2007). New antifouling technologies: Application of barnacle settlement and metamorphosis mechanism studies. Sessile Organisms, 24, 133-139. (in Japanese)

Nogata, Y., N. Tokikuni, E. Yoshimura, K. Sato, N. Endo, K. Matsumura, and H. Sugita (2011). Salinity limitations on larval settlement of four barnacle species. Sessile Organisms, 28, 47-54. (in Japanese)

Ohkawa, K., A. Nishida, H. Sogabe, Y. Sakai, and H. Yamamoto (2000). Characteristics of marine adhesive proteins and preparation of antifouling surfaces for the sessile animals. Sessile Organisms, 17. 13-22.

Sakaguchi, I. (2003). An overview of the antfouling technologies in power plant cooling water systems. Sessile Organisms, 20, 15-19. (in Japanese)

Sakaguchi, I. and T. Namihira (2006). Settlement and growth of barnacles at a power station in Okinawa. Sessile Organisms, 23, 17-23. (in Japanese)

Satuito, C. G., K. Shimizu, K. Natoyama, M. Yamazaki, and N. Fusetani (1996). Age-related settlement success by cyprids of the barnacle Balanus amphitrite, with special reference to consumption of cyprid storage protein. Mar. Biol., 127, 125-130.

Tada, T., H. Noriyasu, Y. Kawamura, Y. Ohkubo, and K. Ogawa (2009). Development of a water- and oil-repellent treatment for silk and cotton fabrics with fluoroalkyltrimethoxysilane. J. Textile Eng., 55, 13-21.

Tsuji, I., Y. Ohkubo, and K. Ogawa (2008). Study on superhydrophobic and oleophobic surfaces prepared by the chemical adsorption technique. J. Surface Finishing Soc. Jpn., 59, 460-464. (in Japanese)

Yamamoto, H., Y. Ohkubo, K. Ogawa, and K. Utsumi (2009). Application of a chemically adsorbed fluorocarbon film to improve demolding. Precision Eng., 33, 229-234.

Yamashita, K. (1990). Attachment of marine organisms on four kinds of metal plates. Mar. Fouling, 8, 35-45. (in Japanese)

Yamashita, K. and K. Kamiya (2006). Power plant and barnacle. In: Latest Study on Balanomorpha, ed. Sessile Organisms Soc. Jpn., Kouseisha Kouseikaku Co., Ltd., Tokyo, pp.209-224. (in Japanese) 